\title{
Flow cytometric assessment of the antimicrobial properties of an essential oil mixture against Escherichia coli
}

\author{
C. Girard ${ }^{1}$, K. Fayolle ${ }^{2}$, S. Kerros ${ }^{1}$ and F. Leriche ${ }^{2,3}$ \\ ${ }^{1}$ Phytosynthese Innovation Centre, 63200 Mozac, France \\ ${ }^{2}$ Université Clermont-Auvergne, VetAgro Sup, INRA, UMR-Fromage UMRF, 15000 Aurillac, France
}

KEY WORDS: antimicrobial properties, essential oils, flow cytometry, colistin, membrane integrity, membrane depolarization, membrane polarity

Received: 8 March 2018

Revised: 15 March 2019

Accepted: 11 June 2019

${ }^{3}$ Corresponding author:

e-mail: francoise.leriche@vetagro-sup.fr

\begin{abstract}
Essential oils are increasingly being used in human health and animal farming as alternatives to antibiotics. The aim of this study was to better understand the mode of antimicrobial action of a natural essential oil mix (EO mix) by comparison with the colistin, as an antibiotic. The growth inhibitory concentration $(\mathrm{GIC})$ of the EO mix and colistin was determined by turbidimetry. Escherichia coli exposed to EO mix and colistin were analysed by flow cytometry using the fluorescent dyes 3,3-diethyloxacarbocyanine iodide $\left(\mathrm{DiOC}_{2}(3)\right)$ to assess membrane potential, and propidium iodide (PI) and SYTO9 to assess membrane integrity following treatment at the $\mathrm{GIC}$ and $1 / 2-\mathrm{GIC}$ of the EO mix every $\mathrm{h}$ for $4 \mathrm{~h}$. At $1 \mathrm{~h}$, treatment with EO mix and colistin resulted in significant cell membrane alteration and depolarization. Membrane integrity measurements identified four sub-populations that were not distributed in the same way between EO mix and antibiotic treated cells. Colistin at GIC and $1 / 2-\mathrm{GIC}$ drastically disintegrated the cells that appeared as debris $(69.8 \%$ of cells were lysed after $1 \mathrm{~h}$ of treatment) whereas the EO mix at GIC altered membrane of a majority of cells $(67.4 \pm 1.3 \%$ of cells were partially altered). Contact with $1 / 2-\mathrm{GIC}$ EO mix led to sub-populations that persisted or recovered a physiological state with intact membrane (from $1 \mathrm{~h}$ to $4 \mathrm{~h}$ of treatment, intact cells increased from 23 to $33 \%$ ). So, it was demonstrated that the EO mix presented antibacterial action against $E$. coli. It altered membrane properties by decreasing its polarity and integrity which were reversible phenomena here.
\end{abstract}

\section{Introduction}

The growing concern regarding sustainable livestock production and 'one health' consideration have pointed out the absolute need to decrease antimicrobial use in animal and human life. Due to the ban of antibiotics as antimicrobial growth promoters (AGP) for animal feed (Regulation (EC) No 1831/2003), phytogenics have emerged as alternative solutions to decrease bacterial resistance and helped to main- tain farm animal performances. Phytogenics are a group of natural feed additives derived from herbs, plants and spices that improve immunity status and animal metabolism and have both antibacterial and antioxidant properties (Hashemi and Davoodi, 2010). Numerous in vivo assays have reported beneficial effect of phytogenics on pigs and poultry zootechnical performances as weight gain, average daily gain and feed conversion ratio (Grela et al., 1998; Demir et al., 2003; Khattak et al., 2014; Kantas et al., 2015). 
Nevertheless, scientific studies testing the efficacy of phytogenics as feed additives have failed to reach consistent conclusions (Tiihonen et al., 2010), which may largely be due to various plant composition dependent on culture conditions. Moreover, the exact mechanism of action of these alternative solutions is not completely known, although the mode of action of their main components has been reported (Gill and Holley, 2004; Somolinos et al., 2010; Alagawany et al., 2015; Yang et al., 2015). A few papers have reported the antimicrobial activity and modulation of monogastric animals (as pigs or poultry) gut flora by essential oils components, using the classical method of turbidimetry and bacterial counts on agar medium but without total elucidation of mechanisms of action, especially in mixture. Indeed, antimicrobial activities of essential oils are ascribed to the chemical complexity of these products, as the resultant activity may be the consequence of a synergistic effect of two or more components acting on different targets (Burt, 2004). Less is known on the mechanisms of antimicrobial action of combinations of two essential oils or their purified components separately. For example, it has been previously reported that essential oils containing aldehydes or phenols, such as cinnamaldehyde, citral, carvacrol, eugenol or thymol as major components, showed the highest antimicrobial activity, followed by essential oils containing terpene alcohols. A mixture of cinnamaldehyde with carvacrol or thymol yielded in most cases synergetic effects against Escherichia coli and Salmonella typhimurium. Furthermore, oregano was the most used essential oil combined with rosemary, thyme, basil, marjoram and lemon balm (Bassolé and Juliani, 2012).

In livestock farming, bacterial pathogens are responsible for animal morbidity, mortality and economic losses (Leclerc et al., 2007). Among them, pathogenic E. coli are Gram-negative bacteria known to be the leading cause of diarrhoea in swine, and respiratory disorder in poultry (Fairbrother et al., 2005). A physiological particularity of Gram-negative bacteria is their bacterial outer membrane (BOM) composed mainly of phospholipids and lipopolysaccharides (LPS). This BOM is a selective permeability barrier that lets nutrients in but keeps undesirable substances out. The BOM maintains bacterial homeostasis and contributes to bacterial metabolic activity such as Adenosine Triphosphate (ATP) synthesis. This additional membrane is also an additional protection against antibacterial agents, which is why the BOM is one of the main targets of antibiotics against Gram-negative bacteria. Colistin, for example, is a polymyxin antibiotic whose mechanism of action is not fully understood but mainly targets the BOM of Gram-negative bacteria (Velkov et al., 2010).

Flow cytometry is a suitably valuable method for unravelling the action of essential oils in comparison to antibiotics. It permits the use of different dyes to visualize the biological functions of bacterial cells, especially viability. Cells with damaged membrane can be enumerated using double red/green staining, and membrane potential can be assessed using specific probes, especially 3,3-diethyloxacarbocyanine iodide $\left(\mathrm{DiOC}_{2}(3)\right)$. Membrane potential (MP) is intimately linked to the energy status of the cell. As a component of the proton motive force, MP is involved in the generation of ATP and has been implicated in such varied processes as bacterial autolysis, glucose transport, chemotaxis and survival at low $\mathrm{pH}$. MPs of metabolically active bacteria are generated by differences in the concentrations of ions on opposite sides of the cell membrane. The ratiometric technique using $\mathrm{DiOC}_{2}(3)$ to assess MP is substantially more accurate and precise than those previously available (direct microelectrode recording), and may be useful in studies on bacterial physiology and investigations on the effects of antibiotics and other agents on microorganisms (Novo et al., 1999). Treatment with proton ionophores such as carbonyl cyanide $m$-chlorophenyl hydrazone (CCCP) used as negative control generally also collapses MP by eliminating the proton gradient across the membrane.

Furthermore, the plate count method could give informative viability results in colony forming units (CFUs) but it only gives a binary viability response either live cells able to grow on plate count media, or all other cells presumed dead. However, it is well documented that under stress conditions a population of bacterial cells will exhibit cell subpopulations with phenotypes that mostly escape this binary live/dead logic. Cells that are injured, viable but not culturable (or 'active but not culturable'), dormant, persisters, etc., cannot be traced or even detected by traditional CFU counts (Hayouni et al., 2008).

So, the aim of the study was to decipher the mode of antimicrobial action of an essential oil mix (EO mix) and colistin on E. coli viability, at growth inhibition concentration and sub-growth inhibition concentration.

\section{Material and methods}

\section{EO mix composition and colistin}

EO mix was provided by Phytosynthese (Mozac, France). It is a blend of natural essential oils having antimicrobial activity against Gram-negative patho- 
gens added in diluted concentrations to animal feed. Its composition was analysed in triplicate using a gas chromatograph (GC) Thermo Fisher Trace GC (Thermo Fischer Scientific, Waltham, MA, USA) coupled to a mass spectrometer (MS) Thermo Fisher DSQ I (Thermo Fischer Scientific, Waltham, MA, USA). Carrier gas was helium used at a flow rate of $0.7 \mathrm{ml} / \mathrm{min}$. Column temperature was initially $60{ }^{\circ} \mathrm{C}$ then gradually ramped up at $5{ }^{\circ} \mathrm{C} / \mathrm{min}$ to reach $300{ }^{\circ} \mathrm{C}$. Diluted $0.5 \mu 1$ samples were injected. The EO mix components were identified by comparing their mass spectra against the NIST 5 mass spectra library (National Institut of Standards and Technology, Gaithersburg, MD, USA)

Colistin was used as reference frame for comparison with the EO mix because it was the first antibiotic known to have antibacterial action against the BOM of Gram-negative bacteria. Stock solutions of colistin sulphate (C4461, Sigma-Aldrich, St. Louis, MI, USA) were prepared by dissolving the antibiotic in sterile water to achieve a concentration of $1 \mathrm{mg} / \mathrm{ml}$ and subsequently diluted $1 / 100$ in Brain Heart Infusion (BHI, BK015, Biokar diagnostics, Allonne, France) broth for further analysis. The EO mix was provided at the initial concentration of $10.417 \mu \mathrm{g} / \mathrm{ml}$.

\section{Bacterial growth inhibition and growth parameters}

Progressive dilutions of ratio 2:1 of colistin or EO mix were prepared in BHI broth from $1 / 2(\mathrm{v} / \mathrm{v})$ to $1 / 16384$ and $294 \mu \mathrm{l}$ of each dilution was dispensed into the well of a 100 well-microtiter plate (Honeycomb microplate, Oy Growth Curves Ab Ltd., Helsinki, Finland). Then, $6 \mu$ of an overnight culture of E. coli (E. coli, CIP: $54.8 \mathrm{~T}$ strain provided by the International Collection of the Pasteur Institute, Paris, France) grown in BHI broth at $37{ }^{\circ} \mathrm{C}$ was added to target an initial bacterial concentration of $10^{6} \mathrm{CFU} / \mathrm{ml}$. Positive controls consisted in E. coli grown in $\mathrm{BHI}$ broth without antimicrobial agent. Negative controls consisted of BHI broth supplemented with EO mix or colistin at different concentrations but not seed with bacteria. All tests were conducted in triplicate. Microtiter plates were incubated at $37^{\circ} \mathrm{C}$ for $18 \mathrm{~h}$ in an automated turbidimeter (Bioscreen C, Labsystems, Helsinki, Finland). OD measurement at $420-580 \mathrm{~nm}$ wavelength band was performed every 15 min after $20 \mathrm{~s}$ shaking. Growth curve data was processed using the free DMFit curve-fitting software v2.1 (courtesy of the Institute of Food Research, Norwich, UK) and the function of Baranyi et al (1993). Mathematical analysis enabled the determination of three growth parameters:
$\mathrm{OD}_{\max }$ data, which gives the maximum increases in OD during incubation, maximum growth rate $\left(\mu_{\max }\right)$, which occurs in the early exponential growth phase, and lag time (Lag T), which is time lapse before an OD increase as per Baranyi et al. (1993) function. Extension of the lag time was calculated with formula of Hayouni et al. (2008), and expressed as a percentage of experiment running time $(18 \mathrm{~h})$.

Growth inhibition concentration (GIC) was defined as the lowest concentration of each antimicrobial agent for which no $E$. coli growth was detectable for $18 \mathrm{~h}$ in liquid broth at $37^{\circ} \mathrm{C}$.

\section{Flow cytometry study}

Cell preparation. BHI broth added with colistin or EO mix at GIC or $1 / 2$ GIC concentrations was inoculated with $1 \mathrm{ml}$ of an E. coli overnight culture for an initial concentration of approximatively $10^{6} \mathrm{CFU} / \mathrm{ml}$. Bacterial cultures were performed at $37^{\circ} \mathrm{C}$ during $4 \mathrm{~h}$. Every hour, $1 \mathrm{ml}$ of bacterial culture was removed for cytometry analysis.

Fluorescent probes and staining protocol. To assess the membrane integrity of the $E$. coli population, bacterial suspensions were double-stained with propidium iodide (PI) and SYTO9 fluorophores premixed in the commercial BacLight ${ }^{\mathrm{TM}}$ kit (Live/ Dead Bacterial Viability BacLight ${ }^{\mathrm{TM}}$ kit, Thermo Fischer Scientific, Waltham, MA, USA). The preparation was performed following the manufacturer's protocol. Briefly, $1.5 \mu 1$ of PI and $1.5 \mu 1$ of SYTO9 were added to each sample $(1 \mathrm{ml})$ and incubated for $15 \mathrm{~min}$ at room temperature in the dark. Isopropanol (70\%)-treated cells ( $\mathrm{v} / \mathrm{v}$ for $30 \mathrm{~min}$ ) were used as positive controls.

Membrane potential was assessed in the same way but using 3, 3'-diethyloxacarbocyanine iodide $\left(\mathrm{DiOC}_{2}(3)\right)$ as fluorophore (BacLight ${ }^{\mathrm{TM}}$ Bacterial membrane potential kit, Thermo Fischer Scientific, Waltham, MA, USA). The preparation was performed following the manufacturer's protocol. Briefly, $10 \mu \mathrm{l}$ of $\mathrm{DiOC}_{2}(3)$ was added to each sample $(1 \mathrm{ml})$ and incubated in the dark at room temperature for $30 \mathrm{~min}$. The depolarized control consisted of untreated E. coli bacteria added with $10 \mu \mathrm{l}$ of CCCP (BacLight ${ }^{\mathrm{TM}}$ Bacterial membrane potential kit, Thermo Fischer Scientific, Waltham, MA, USA). CCCP is a proton ionophore that eliminates the proton gradient across the membrane (Novo et al., 1999).

Flow cytometry conditions and data analyses. Flow Cytometry (FCM) analyses were performed using a CyFlow $^{\circledR}$ Space system (Partec GmbH, Münster, Germany). Acquisition was performed with Flowmax ${ }^{\circledR}$ (Partec GmbH, Münster, Germany) 
and based on light-scatter and fluorescence signals with 488-nm excitation from a blue solid-state laser delivering illumination at $100 \mathrm{~mW}$. In the flow cytometer, optical filters were set up so that PI was measured above $630 \mathrm{~nm}$, SYTO9 at $520 \mathrm{~nm}$ and $\mathrm{DiOC}_{2}(3)$ at 527 and $590 \mathrm{~nm}$. The trigger was set for the forward scatter (FSC) and data were acquired on two parameters, i.e. dot plots of green fluorescence (FL1 at $520 \mathrm{~nm}$ ) versus red fluorescence (FL2 at $630 \mathrm{~nm}$ ) or forward scatter versus sideward scatter (SSC). FSC, SSC and fluorescence signals of individual cells passing through the illuminated zone were collected as logarithmic signals. Data were analyzed using the Flowmax ${ }^{\circledR}$ software (Partec $\mathrm{GmbH}$, Münster, Germany). The Live/Dead ${ }^{\mathbb{R}}$ staining method was used to evaluate the effect of antimicrobial compounds on $E$. coli membrane integrity. It consists of two stains, PI and SYTO9 that stain nucleic acid. PI is a red intercalating stain that cannot penetrate or is excluded by healthy cells, whereas SYTO9 is a green intercalating membrane permeant molecule that stains all cells, i.e. both those with intact membrane and those with damaged membrane (Stiefel et al., 2015). When the two stains are present within a cell, PI causes a reduction in the SYTO 9 stain fluorescence. Indeed, PI has a stronger affinity for nucleic acid but, when the two stains are present within a cell, SYTO9 can be displaced from nucleic acid and the cells will fluoresce in red. (Stocks, 2004). Thus, in the presence of both stains and under fluorescence excitation at $488 \mathrm{~nm}$, bacteria with intact cell membranes appear fluorescent green, whereas membrane-compromised bacteria appear red. However, it is now admitted that the FCM analysis of these double-stained bacterial cultures allows the distinction of the four cell sub-populations: intact cells, membrane-partially compromised cells, membrane-compromised cells and lysed cells (Manini and Danovaro, 2006). Our clustering was based on this approach: after SYTO9/PI staining. Membrane potential variations were assessed using $\operatorname{DiOC}_{2}(3)$, a cationic dye, that exhibits a green fluorescence in all bacteria and shifts towards red emission due to self-association of dye molecules in dependency of the MP (high MP -increased red fluorescence) (Novo et al., 1999). So, the red fluorescence is an indicator of both cell size and membrane potential, while the green fluorescence is only affected by cell size. Red-to-green $\mathrm{DiOC}_{2}(3)$ fluorescence ratio (R:G) therefore gives MP levels normalized to cell size. Ratio analysis of $\mathrm{DiOC}_{2}(3)$ stains was performed according to Novo et al. (1999). For this analysis, red fluorescence intensity and green fluorescence intensity with maximum emission at $590 \mathrm{~nm}$ and $527 \mathrm{~nm}$, respectively, were collected by FCM. R:G ratios were calculated from mean FCM fluorescence intensities measured every hour for $4 \mathrm{~h}$.

Following Berney et al. (2007), the density plots obtained by flow cytometric analysis were divided into four regions (gates), each assigned to cells with different physiologic properties. The gate scheme is reported in Table 1 .

The ratio of mean red to mean green $\mathrm{DiOC}_{2}(3)$ fluorescence channel value was calculated to investigate changes in membrane potential. Following Novo et al. (1999), it was assumed that the red/ green ratio of untreated cells represents the relative membrane potential of intact cells. Reduction of red/green ratio indicates loss cell membrane potential.

Table 1. Gating scheme for cells stained with propidium iodide (PI) and SYTO9, according to Berney et al. (2007)

\begin{tabular}{|c|c|c|}
\hline Gate & $\begin{array}{l}\text { Fluorescence } \\
\text { properties of cells }\end{array}$ & $\begin{array}{l}\text { Possible explanation of the status of } \\
\text { involved cellular mechanism }\end{array}$ \\
\hline Q4 & PI- SYTO9+ & viable cells, intact membrane \\
\hline Q2 & SYTO9+ & $\begin{array}{l}\text { semi-permeabilized cells, damaged } \\
\text { membrane }\end{array}$ \\
\hline Q1 & SYTO9- & $\begin{array}{l}\text { permeabilized cells, compromised } \\
\text { membrane }\end{array}$ \\
\hline Q3 & SYTO9- & debris, lysed cells \\
\hline
\end{tabular}

\section{Fluorescence microscopy images}

The E. coli cultures were prepared in presence of EO mix or colistin in the same way as for the cytometric study. The $E$. coli cells were treated for $1 \mathrm{~h}$ with the concentration corresponding to the GIC value of the EO mix or colistin, then collected by centrifugation at $10000 \mathrm{~g}$ for $10 \mathrm{~min}$ and washed once in apyrogenic water $\left(\operatorname{Versol}^{\circledR}\right.$, Aguettant, Lyon, France). The cells were then suspended in $1 \mathrm{ml}$ of apyrogenic water and filter on an Isopore ${ }^{\mathrm{TM}}$ polycarbonate membrane filter (pore size $0.2 \mu \mathrm{m}$ ) (Millipore, Burlington, MA, USA). The membrane was fixed on a slide and observed with a FITC filter (fluorescein isothiocyanate filter for green fluorescence detection) on a BX 41 fluorescence microscope (Olympus, Tokyo, Japan). Digital images were acquired with a U-TV0.35XC-2 camera (Olympus, Tokyo, Japan).

\section{Bacterial counts and viability reduction}

Serial dilutions of bacterial cultures in peptone water with or with colistin or EO mix at GIC or $1 / 2$-GIC concentrations were inoculated on BHI agar (Oxoid, Basingstoke, UK) and incubated for 
$24 \mathrm{~h}$ at $37^{\circ} \mathrm{C}$. Analysis was performed in duplicate. Viability reduction was calculated as:

$$
\left(1-\mathrm{N}_{\mathrm{T}} / \mathrm{N}_{\mathrm{C}}\right) \times 100 \text {, }
$$

where: $\mathrm{N}_{\mathrm{T}}$ - bacterial count in the treated sample and $\mathrm{N}_{\mathrm{C}}$ - bacterial count in the untreated sample.

\section{Statistical analysis}

Lag time and the maximal growth rate values, calculated from bacterial growth parameter data, were compared by a Wilcoxon non-parametric statistical hypothesis test using $\mathrm{R}$ software for Windows v.3.4.2 (http://cran.r-project.org/). Differences were considered statistically significant at $P<0.05$.

\section{Results}

\section{EO mix composition}

EO mix analysis by GC-MS showed that the commercial preparation is formed of 8 major components representing $95.76 \%$ of total content (Table 2), the key one being cinnamaldehyde (57.56\%), thymol $(9.15 \%)$, carvacrol $(8.84 \%)$.

Table 2. Chemical composition of the essential oil mix (gas chromatography-mass spectrometry analysis)

\begin{tabular}{lc}
\hline Components & Mean content, \% \\
\hline Cinnamaldehyde & $57.56 \pm 0.30$ \\
Thymol & $9.15 \pm 0.10$ \\
Carvacrol & $8.84 \pm 0.09$ \\
p-Cymene & $7.31 \pm 0.10$ \\
Eugenol & $6.56 \pm 0.13$ \\
-Terpinene & $3.57 \pm 0.04$ \\
Diallyl disulfide & $1.41 \pm 0.02$ \\
B-Caryophyllene & $1.33 \pm 0.03$
\end{tabular}

\section{$E$. coli growth parameters in presence of antimicrobials}

EO mix GIC was $781.2 \pm 0.02 \mu \mathrm{g} / 1$ and colistin GIC was $0.434 \pm 0.18 \mu \mathrm{g} / \mathrm{l}$.

The extension of lag time was used as indicator to compare the antimicrobial effects of EO mix and colistin on E. coli growth at GIC and $1 / 2$-GIC. E. coli lag time with either EO mix GIC or colistin GIC were $71.5 \%$ longer than the control (E. coli without antimicrobial) $(P<0.05)$ (Figure 1).

E. coli lag time with $1 / 2$-GIC EO mix was $34.7 \%$ longer than the control. The E. coli lag time at $1 / 2$-GIC colistin was not statistically significant in comparison to control. The extension of E. coli lag time was greater with $1 / 2$-GIC EO mix $(30.3 \%)$ than with $1 / 2$-GIC colistin (10.7\%).

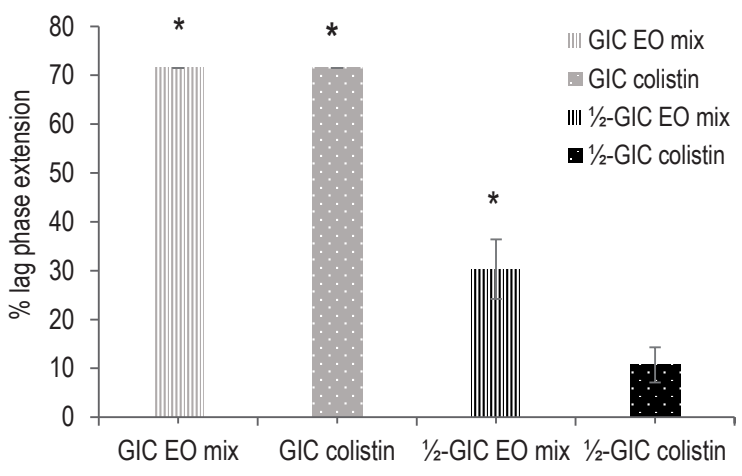

Figure 1. Extensions in the lag phases of growth of the studied $E$. coli cells when incubated with growth inhibitory concentration (GIC) or $1 / 2-\mathrm{GIC}$ of essential oil (EO) mix or colistin

Lag phases were first estimated using DMFit software based on the model of Baranyi et al. (1993), then normalized by expressing them as a percentage of the run time of the experiment $(18 \mathrm{~h}) ;{ }^{*}$ - indicates the groups statistically different from control $(P<0.05)$

E. coli maximal growth rate was significantly lower than control with $1 / 2$-GIC EO mix $(P<0.05)$ but not significantly different to control with $1 / 2$ - GIC colistin $(P>0.05)$ (data not shown).

For the following experiments, bacteria were studied after contact with EO mix or colistin at GIC or $1 / 2$-GIC, so bacterial populations were in the lag phase.

\section{Effect of EO mix or colistin on $E$. coli membrane integrity}

The FCM analysis of E. coli cells grown in BHI without biocide (negative control) showed that less than $6 \%$ of bacterial population was lysed or damaged (Figure 2A). For isopropanol treated cells, FCM analysis showed that $99 \%$ of cells, appeared lysed (Figure 2B). These results were validated by fluorescence microscopy analysis (Figure 3).

\section{EO mix at GIC}

Before antimicrobial treatment, E. coli cells were in the exponential growth phase and most of cells presented an intact membrane (94.2\%) (Figure 4A). After 1-h treatment with EO mix at GIC, most of the cells showed partially altered membrane $(67.4 \pm 1.3 \%)$. The proportion of membranecompromised cells was $10.6 \%$. The lysed cells represented $18.2 \%$. The proportion of intact cells dropped to $4 \%$. After $2 \mathrm{~h}$ of contact, proportion of membrane-partially compromised cells decreased to about $40 \%$, proportion of membrane-compromised cells decreased $(1.4 \%)$, proportion of lysed cells increased to $27 \%$, and proportion of intact cells increased 8 -fold (31.8\%). Then, from 2 to $4 \mathrm{~h}$ of contact, proportion of intact cells increased slowly. 
A

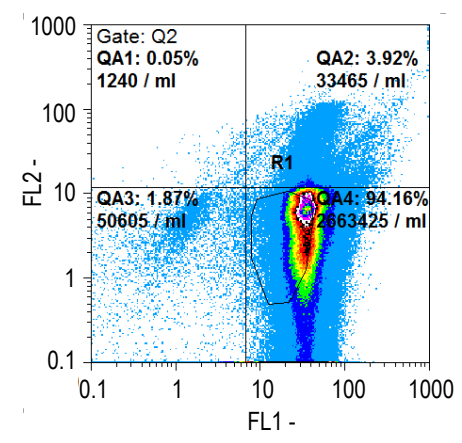

B

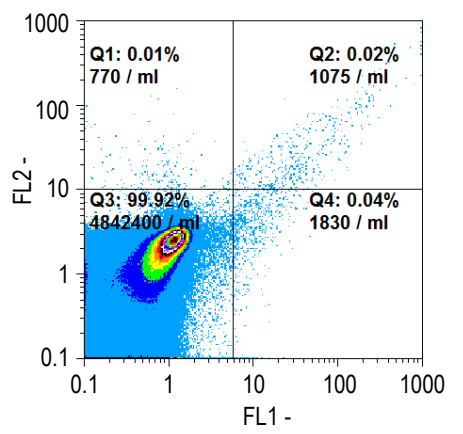

Figure 2. Flow cytometry profiling of E. coli after SYTO9 and Propidium lodide staining. (A) Cytogram of the green (FL1) and red (FL2) fluorescence signals of untreated $E$. coli cells $\left(2 \mathrm{~h}\right.$ incubation at $\left.37^{\circ} \mathrm{C}\right)$, (B) Cytogram of the green (FL1) and red (FL2) fluorescence signals of $E$. coli treated with isopropanol up to $30 \mathrm{~min}$
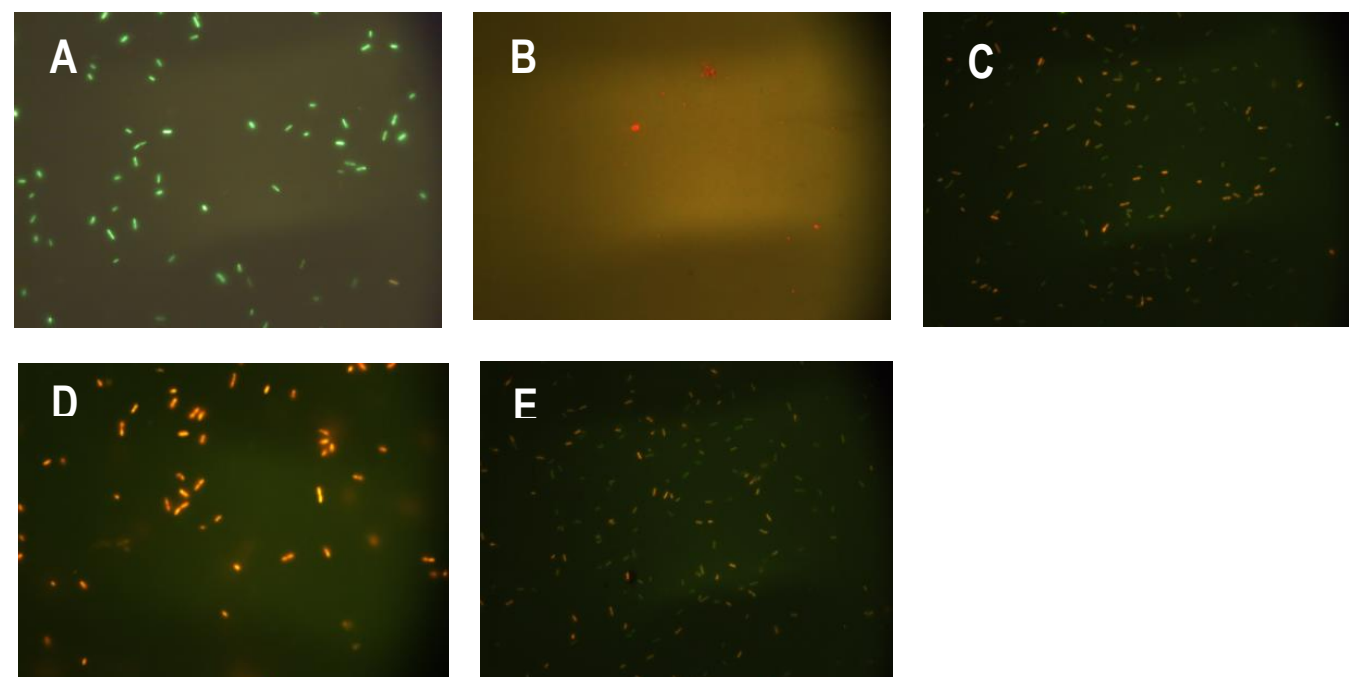

Figure 3. Light microscopy image of $E$. coli cells stained with $1.5 \mu$ of SYTO9 and $1.5 \mu$ of Propidium lodide: (A) untreated $E$. coli cells incubated at $37^{\circ} \mathrm{C}$ for $1 \mathrm{~h}$; (B) lysed $\mathrm{E}$. coli cells after treatment with isopropanol for $30 \mathrm{~min}$; (C) E. coli cells incubated with essential oil (EO) mix at growth inhibitory concentration (GIC) for $1 \mathrm{~h}$; (D) E. coli cells incubated with EO mix at $1 / 2-\mathrm{GIC}$ for $1 \mathrm{~h}$; (E) E. coli cells incubated with colistin at GIC for $1 \mathrm{~h}$

(from 31.8 to $36.5 \%$ ). After 3 and $4 \mathrm{~h}$ of contact, the proportions of lysed, membrane-partially compromised and intact cells were equivalent $(\sim 30 \%)$ and percentage of membrane-compromised cells remained weak $(0.2 \%)$.

\section{EO mix at $1 / 2$ GIC}

After 1-h treatment with EO mix at $1 / 2$-GIC (Figure $4 \mathrm{~B})$, most of the cells showed partially altered membrane $(61.4 \%)$. The proportion of membranealtered cells was $3.8 \%$. Lysed cells represented $11.2 \%$ of total population, while the proportion of intact cells fell to $23.1 \%$. After $2 \mathrm{~h}$ of contact, the proportion of lysed, membrane-partially compromised and intact cells remained stable $(13,58$ and $24 \%$, respectively), and proportion of membranecompromised cells increased slightly $(5.1 \%)$. At $3 \mathrm{~h}$ of contact, the proportions of lysed, membranecompromised and partially compromised cells had slightly decreased, and consequently the proportion of intact cells increased (29.4\%). After $4 \mathrm{~h}$ of contact, the proportion of lysed, membrane-compromised and partially compromised cells dropped to $12.6,1.7$ and $52.4 \%$, respectively, whereas proportion of intact cells rose to $33.1 \%$.

\section{Colistin at GIC}

After 1-h treatment with colistin at GIC (Figure $4 \mathrm{C})$, most of cells were lysed (69.8\%). The proportion of membrane-compromised cells was $16.3 \%$. The membrane-partially compromised cells represented $13.5 \%$ of total population while the proportion of intact cells fell to $0.5 \%$. After $2 \mathrm{~h}$ of contact, proportion of lysed cells increased $(71.3 \%)$, proportion of membrane-compromised cells decreased slightly (14.6\%), proportion of membrane-partially compromised remained stable $(13.8 \%)$ and proportion of intact cells decreased slightly $(0.4 \%)$. 
A

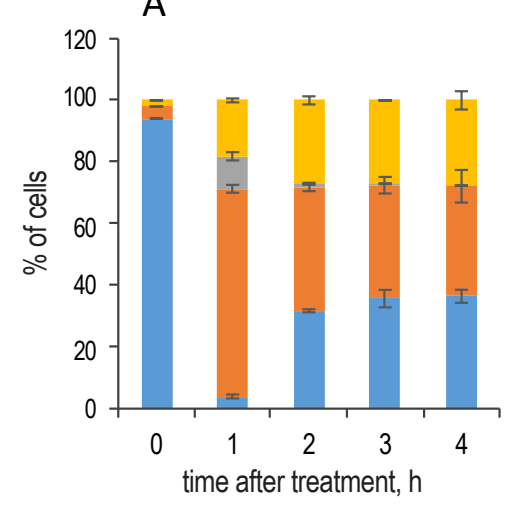

C

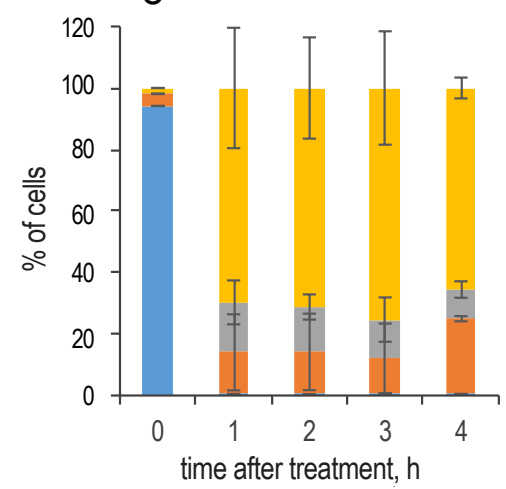

B

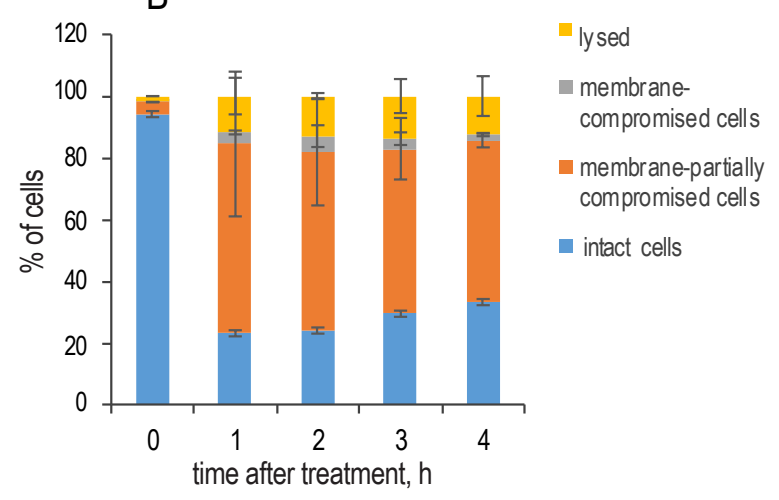

D

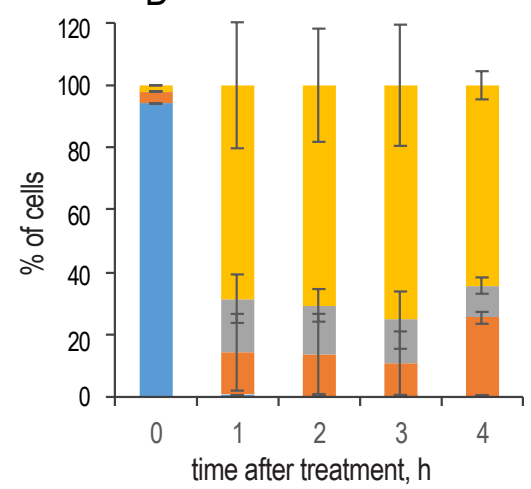

Figure 4. Percentages of $E$. coli cell subpopulations (lysed cells, membrane-compromised cells, membrane-partially compromised cells and intact cells) before and after essential oil (EO) mix treatment at (A) growth inhibitory concentration (GIC) and (B) $1 / 2$-GIC and after colistin treatment at (C) GIC and (D) $1 / 2-\mathrm{GIC}$

bars are means \pm standards deviation of two independent experiments

After $3 \mathrm{~h}$ of contact, all proportions were stable. After $4 \mathrm{~h}$ of contact, proportion of lysed cells was $65.6 \%$, proportion of membrane-compromised cells decreased to $9.5 \%$, and proportion of partially compromised cells increased to $24.6 \%$ while proportion of intact cells remained stable (0.4\%).

\section{Colistin at $1 / 2$-GIC}

The 4 different subpopulations of $E$. coli cells were distributed in the same proportions as with colistin at GIC (Figure 4D).

\section{Comparison of EO mix vs colistin at GIC or $1 / 2$-GIC}

After $1 \mathrm{~h}$ of contact, the proportion of lysed cells was much higher with colistin at GIC than with EO mix at GIC. The proportion of membrane-compromised cells was equivalent between EO mix and colistin at GIC. The proportion of membrane-partially compromised cells was much higher with EO mix than colistin at GIC. The proportion of intact cells was higher with EO mix than with colistin at GIC. From 2 to $4 \mathrm{~h}$ of contact, the proportion of lysed cells remained higher with colistin than with EO mix at GIC.
The proportion of membrane-compromised cells was higher with colistin than with EO mix at GIC. The proportion of membrane-partially compromised cells was much higher with EO mix than with colistin at GIC. Whatever the time of contact, the proportion of intact cells was higher with $\mathrm{EO}$ mix than with colistin at GIC. Cell distributions with EO mix and colistin at $1 / 2$-GIC followed the same trends.

\section{Effect of EO mix and colistin on $E$. coli membrane potential (MP)}

Positive control (E. coli treated with CCCP (carbonyl cyanide $m$-chlorophenylhydrazone), a proton ionophore that reduced to zero the membrane potential) showed a low R:G value (0.09) whereas negative control (exponential growth phase E. coli) showed the highest $\mathrm{R}: \mathrm{G}$ ratio $(0.85)$.

After $1 \mathrm{~h}$ of contact with EO mix at GIC (Figure $5 \mathrm{~A}), \mathrm{R}: \mathrm{G}$ ratio was 0.19 and less than negative control (0.85). From $1 \mathrm{~h}$ to $3 \mathrm{~h}$ of contact with EO mix at GIC, R:G ratio increased to 0.35 and stabilized at 0.33 after $4 \mathrm{~h}$ of contact. Throughout the experiment, $R: G$ ratio remained lower than in the negative control. 
A

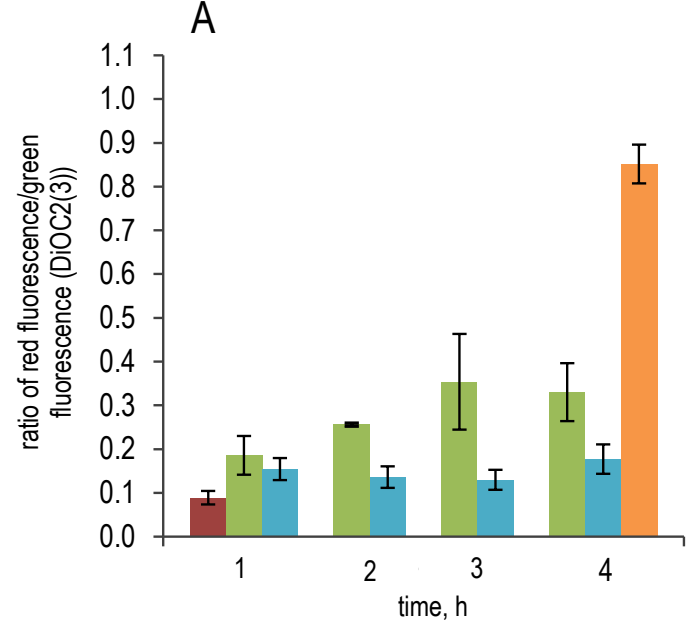

B

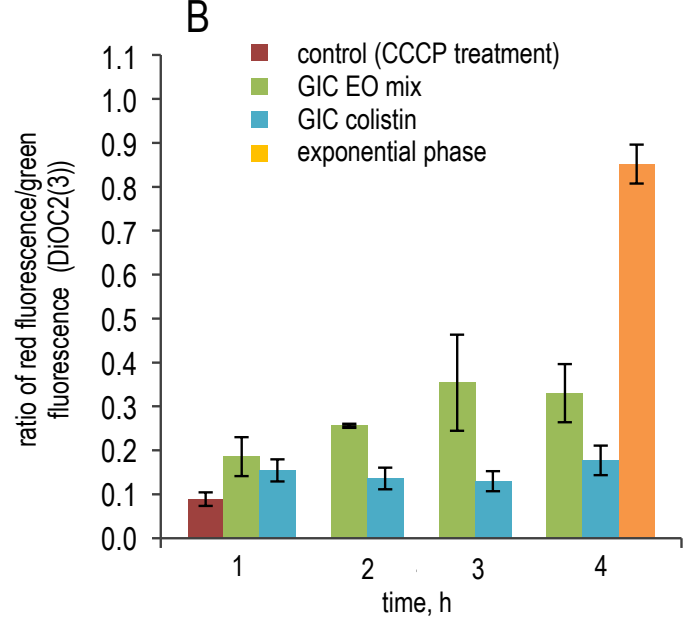

Figure 5. Ratios of red fluorescence/green fluorescence (DiOC2(3)) assessed by flow cytometry of $E$. coli treated with (A) essential oil (EO) mix at growth inhibitory concentration (GIC) or colistin at GIC and (B) EO mix at $1 / 2-\mathrm{GIC}$ or colistin at $1 / 2-\mathrm{GIC}$

bars are means \pm standard deviation of two independent experiments

CCCP (carbonyl cyanide m-chlorophenylhydrazone) is a proton ionophore that reduced to zero the membrane potential

Between $1 \mathrm{~h}$ and $3 \mathrm{~h}$ of contact with EO mix at $1 / 2$-GIC (Figure 5B), R:G ratio remained stable at 0.13-0.14 and lower than in the negative control. However, after $4 \mathrm{~h}$ of contact, $\mathrm{R}: \mathrm{G}$ ratio had increased sharply to 0.94 and was higher than the R:G ratio of negative control.

These results show that the EO mix at GIC induced the depolarization of $E$. coli membrane after $4 \mathrm{~h}$ of contact, whereas EO mix at $1 / 2$-GIC was only able to depolarize $E$. coli cells after $3 \mathrm{~h}$ of contact. At $4 \mathrm{~h}$ of contact with EO mix at $1 / 2$-GIC, E. coli cells were able to recover high MP.

From 1 to $4 \mathrm{~h}$ of contact with colistin at GIC or at $1 / 2$-GIC, R:G ratio was stable and lower than the $\mathrm{R}: \mathrm{G}$ ratio of negative control. These results showed that colistin depolarized $E$. coli cells to maintain a low MP during $4 \mathrm{~h}$.

These findings highlight the fact that both antimicrobials are able to depolarize $E$. coli membrane at GIC during $4 \mathrm{~h}$, but at $1 / 2-\mathrm{GIC}$, only colistin is able to maintain a low MP during $4 \mathrm{~h}$. With EO mix at $1 / 2$ - GIC, E. coli cells recover a high MP.

\section{Viability reduction}

According to classical agar plate count methods, cell culturability is the indicator of cell viability, as the method consider that only two populations exist: those that are viable and so are able to form colonies on agar plates, and the others that are not. The effects of antimicrobials are assessed as the loss of viability that they induce on a bacterial population.

After $1 \mathrm{~h}$ of contact with EO mix at GIC (Table 3), viability reduction was $99.9 \%$. After $2 \mathrm{~h}$ of contact with EO mix at GIC, viability reduction
Table 3. Percentage of lysed, membrane-compromised and membrane-partially compromised Escherichia coli cells as assessed by flow cytometry and viability reduction of $E$. coli as evaluated by means of the drop-plating method after different treatments with essential oil (EO) mix (GIC or $1 / 2$-GIC) or colistin (GIC or $1 / 2$-GIC)

\begin{tabular}{|c|c|c|c|c|}
\hline Treatment & Concentration & $\begin{array}{l}\text { Contac } \\
\text { time, } h\end{array}$ & $\begin{array}{l}\% \text { lysed, per- } \\
\text { t meabilized and } \\
\text { partially permea- } \\
\text { bilized cells }\end{array}$ & $\begin{array}{l}\% \text { viability } \\
\text { - reduction }\end{array}$ \\
\hline \multirow{4}{*}{$\begin{array}{l}\text { Control (un- } \\
\text { treated E. coli) }\end{array}$} & - & 1 & $5.8 \pm 0.0$ & - \\
\hline & & 2 & $1.5 \pm 0.0$ & _ \\
\hline & & 3 & $1.0 \pm 0.0$ & _- \\
\hline & & 4 & $1.3 \pm 0.0$ & - \\
\hline \multirow[t]{8}{*}{ EO mix } & GIC & 1 & $96.1 \pm 0.2$ & $99.9 \pm 0.4$ \\
\hline & & 2 & $68.3 \pm 0.2$ & $100.0 \pm 0.0$ \\
\hline & & 3 & $64.3 \pm 1.0$ & $100.0 \pm 0.0$ \\
\hline & & 4 & $63.7 \pm 0.8$ & $100.0 \pm 0.0$ \\
\hline & $1 / 2-G I C$ & 1 & $76.9 \pm 6.1$ & $80.7 \pm 0.9$ \\
\hline & & 2 & $76 \pm 6.6$ & $92.1 \pm 4.8$ \\
\hline & & 3 & $70.5 \pm 5.8$ & $96.1 \pm 2.0$ \\
\hline & & 4 & $66.9 \pm 1.5$ & $76.2 \pm 2.7$ \\
\hline \multirow[t]{8}{*}{ Colistin } & $\mathrm{GIC}$ & 1 & $99.5 \pm 6.5$ & $97.4 \pm 1.1$ \\
\hline & & 2 & $99.3 \pm 5.5$ & $99.9 \pm 1.6$ \\
\hline & & 3 & $99.6 \pm 6.2$ & $100.0 \pm 0.0$ \\
\hline & & 4 & $99.6 \pm 1.2$ & $100.0 \pm 0.0$ \\
\hline & $1 / 2-G I C$ & 1 & $99.5 \pm 6.7$ & $99.3 \pm 0.3$ \\
\hline & & 2 & $99.7 \pm 6.0$ & $100.0 \pm 0.2$ \\
\hline & & 3 & $99.7 \pm 6.5$ & $100.0 \pm 0.1$ \\
\hline & & 4 & $99.6 \pm 1.5$ & $100.0 \pm 0.0$ \\
\hline $\begin{array}{l}\text { E. coli treated } \\
\text { at } 70^{\circ} \mathrm{C}\end{array}$ & & 0.5 & $98.1 \pm 0.0$ & $100.0 \pm 0.0$ \\
\hline $\begin{array}{l}\text { E. coli treated } \\
\text { with isopropanol }\end{array}$ & & 0.5 & $99.9 \pm 0.0$ & $100.0 \pm 0.0$ \\
\hline
\end{tabular}

GIC - growth inhibitory concentration 
increased to $100 \%$ and remained stable until $4 \mathrm{~h}$. After $1 \mathrm{~h}$ of contact with EO mix at $1 / 2-\mathrm{GIC}$, viability reduction was lower at $80.7 \%$. Between $1 \mathrm{~h}$ and 3 h of contact, viability reduction increased slowly to $96.1 \%$, but after $4 \mathrm{~h}$ of contact had dropped to $76.2 \%$.

After $1 \mathrm{~h}$ of contact with colistin at GIC (Table 3), viability reduction was lower at 97.4\%. Between $1 \mathrm{~h}$ and $4 \mathrm{~h}$ of contact, viability reduction increased to $100 \%$. After $1 \mathrm{~h}$ of contact with colistin at $1 / 2$-GIC, viability reduction was $99.3 \%$. Between $1 \mathrm{~h}$ and $4 \mathrm{~h}$ of contact, viability reduction increased to $100 \%$.

At GIC, both antimicrobials totally reduced culturability during $4 \mathrm{~h}$. At 1/2-GIC, only colistin was able to totally decrease $E$. coli culturability. With EO mix at $1 / 2-$ GIC, a minor fraction of $E$. coli cells remained culturable during $4 \mathrm{~h}$.

\section{Discussion}

The aim of this study was to investigate and compare the effects of 4-hour contact exposure on $E$. coli cells between an EO mix and colistin using a combination of classical methods and flow cytometric analysis coupled with specific cell fluorescence labelling. In a first step, turbidimetric growth monitoring of $E$. coli in the presence of the antimicrobials served to determine the minimum GIC. Experiments were then performed with the EO mix and colistin at GIC and 1/2-GIC.

When $E$. coli cells were in contact with EO mix at GIC for $4 \mathrm{~h}$, none of the cells was cultivable on agar plate in our experimental conditions. However FCM analysis revealed physiological heterogeneity within this cell populations. By reference to Manini and Danovaro (2006) we could distinguish four distinct regions on cytograms and assigned as: intact, lysed, membrane-compromised or membrane-partially compromised. Similar findings were described by Stiefel et al. (2015) who consider isopropanol treated cells as dead and as good standard to manage the fluorescence data gating. Indeed, $36.5 \%$ of cells were considered as intact, $27 \%$ as dead and $35.75 \%$ presented with different degrees of damage as estimated after PI/SYTO9 staining. Cells exhibited a marked MP decrease. The total loss of viability on agar plates and the presence of intact cells observed by FCM indicated the presence of cells that maintained membrane integrity but were unable to grow on agar plates. This fraction of $E$. coli cells had probably entered the Viable-But-Not-Cultivable (VBNC) state. VBNC cells are therefore defined as the bacterial cells that do not form colonies when standard culturing techniques are applied but still retain metabolic activities (Oliver, 2010). Several authors have also shown that VBNC cells have a complete membrane structure that ensure the genetic information is not lost but several components of the cell wall are modified such as, for example, the fatty acids composition and organisation (Linder and Oliver, 1989). The fact that VBNC cells retaining high MP is still controversy (Paparella et al., 2008). However, MP measurement is not the only parameter proving metabolic bacterial activity, and other viability parameters should be explored to inform firm conclusions. Concerning essential oils, our results are consistent to those described by Bouhdid et al. (2009) who showed that the Origanum compactum essential oil caused complete growth inhibition of Pseudomonas aeruginosa accompanied by a collapse of cell MP and loss of membrane permeability after $1 \mathrm{~h}$ of contact.

Turbidimetry results showed that EO mix at $1 / 2$-GIC induced an extension of the lag phase. This was considered as reflecting the bacteriostatic effect of the studied antimicrobials on E. coli. Lag phase lasted to beyond the duration of the FCM experiment: the FCM results were thus observed during the lag phase.

In the presence of EO mix at $1 / 2-G I C, E$. coli membrane was altered but with less damage than with EO mix at GIC in terms of percentage of permeabilized cells $(3.75 \%$ of permeabilized cells at $1 \mathrm{~h}$ of contact with EO mix at $1 / 2$-GIC vs $10.55 \%$ with EO mix at GIC). This was consistent with the concentration-dependent action highlighted in the turbidimetric analysis.

Between $1 \mathrm{~h}$ and $3 \mathrm{~h}$ of contact, the incomplete loss of viability on agar plates and the presence of intact cells observed by FCM indicated that a fraction of cells was able to maintain membrane integrity and culturability, but MP still remained very low up to $3 \mathrm{~h}$ of contact.

After $4 \mathrm{~h}$ of contact, culturability, proportion of intact cells and MP all rose concurrently. Furthermore, considering the growth parameters determined by Bioscreen $C$, the cells were still in lag phase. These findings suggested that a fraction of intact cells never lost their culturability and a fraction of damaged cells were able to restore their membrane integrity and MP. This is in agreement with Paparella et al. (2008) who showed that injured cells can recover and regain a physiologically active state.

With colistin at GIC and 1/2-GIC we observed a good correlation between percentage of PI-stained 
E. coli (including lysed, membrane-compromised and partially compromised cells) measured by FCM and the viability reduction of $E$. coli measured by agar plate counts. FCM analysis of DiOC2(3)stained strains showed that in presence of colistin the observed loss of viability of $E$. coli could be correlated to membrane depolarization and membrane alteration which is consistent with previous studies (Velkov et al., 2013).

Comparison between the EO mix and colistin based on E. coli growth monitoring with the turbidity method showed that both antibacterials had a bacteriostatic effect on E. coli (extension of lag phase). FCM analysis specified the antimicrobial effect on E. coli cell by cell. The presence of VBNC, i.e. with intact membrane but nonculturable, with $\mathrm{EO}$ mix at GIC showed that EO mix targeted other components of $E$. coli cells. On the other hand, the presence of high proportions of lysed cells with colistin at GIC or $1 / 2$-GIC indicated that the colistin effect mostly led to cytoplasmic membrane disruption and cell lyse.

The observed difference between colistin and EO mix effects against $E$. coli could be explained by their biochemical compositions. The main components of the used EO mix were cinnamaldehyde, carvacrol and thymol. Cinnamaldehyde, the main component of cinnamon oil, is an aldehyde, and its antibacterial activity is not attributable to one specific mechanism like inhibition of the membranebound ATPase or others enzyme activities. Indeed, this antimicrobial agent is well known to target different parts of the cell (Shen et al., 2015). Carvacrol and thymol are terpenoid components and are structurally isomeric. Their hydroxyl group and the presence of delocalized electrons are known to be important for their antimicrobial activity (Nazzaro et al., 2013). Cinnamaldehyde, carvacrol and thymol have been extensively studied for their antimicrobial activity, notably on Gram-negative bacteria. They have been shown to induce BOM disintegration and depolarization (Xu et al., 2008), even though neither thymol nor carvacrol act as direct permeabilizing agent. Indeed, even if BOM is impermeable to hydrophobic components, small molecules can get through it using porines (Nazzaro et al., 2013; Shen et al., 2015). Unlike many antibiotics, the hydrophobic character of essential oils components also allows them to penetrate BOM by accumulation in the lipid bilayer (Helander et al., 1998). As bacteria are unable to separate essential oil components from the lipid bilayer, functional interactions between proteins and lipids are disturbed, leading to the cell membrane alteration (Mikulášová et al.,
2016). Di Pasqua et al. (2006) also suggested that bacteria exposed to carvacrol are able to change their membrane fatty acid composition leading to a modification of cell membrane integrity. However, even though each of the major compounds of the EO mix possess one or several mechanisms of bacterial growth inhibition, there may still be antagonistic or synergetic effects between components (Bouhdid et al., 2009). These possible multiple targets and combined effects could also explain the successive physiological states observed here in relation to membrane damage and depolarization. Either way, our study confirmed the antimicrobial action of the EO mix at the tested concentrations on E. coli cell membrane integrity.

Colistin (polymyxin E) is a polymyxin-class antibiotic (Velkov et al., 2010). Its bactericidal activity is well documented, but its exact mechanisms of action are still unknown (Yahav et al., 2012). Nevertheless, several of its initial targets have been described. Colistin acts as a surfactant component and its first targets are the lipopolysaccharides (LPS) in the BOM (Velkov et al., 2010), which explains why its antibacterial action is restricted to Gram-negative bacteria. The colistin molecule with five positive charges interacts strongly with LPS phosphate groups via electrostatic interactions and then inserts its hydrophobic chain into the BOM via hydrophobic interactions ( $\mathrm{Ku}$ et al., 2015). This induces an alteration of the physical integrity of phospholipid bilayer (Ku et al., 2015). A secondary mode of action of polymyxins was described by Deris et al. (2014) who showed that polymyxin inhibits type II NADH:quinone oxidoreductase (NDH-2) in a concentration-dependent manner.

\section{Conclusions}

It was explained how an essential oil (EO) mix can inhibit Escherichia coli growth in vitro. It was demonstrated using flow cytometry and specific staining that the EO mix has a bacteriostatic action in vitro against $E$. coli at growth inhibitory concentration (GIC) and even sub-GIC, with heterogeneous effects on cell membrane alteration and membrane depolarization. Its bacteriostatic action appears sufficient to make it effective at limiting $E$. coli growth in vitro. Comparison against colistin led to conclude that the EO mix may not exclusively target the bacterial outer membrane, as staining revealed different dynamics of bacterial viability states, in contrast to colistin which showed a straight bacteriocidal activity against $E$. coli. 


\section{References}

Alagawany M., Abd El-Hack M.E., Farag M.R., Tiwari R., Dhama K., 2015. Biological effects and modes of action of carvacrol in animal and poultry production and health - a review. Adv. Anim. Vet. Sci. 3(2s), 73-84, https://doi.org/10.14737/journal. aavs/2015/3.2s.73.84

Baranyi J., McClure P.J., Sutherland J.P., Roberts T.A., 1993. Modeling bacterial growth responses. J. Ind. Microbiol. 12, 190-194, https://doi.org/10.1007/BF01584189

Bassolé I.H.N., Juliani H.R., 2012. Essential oils in combination and their antimicrobial properties. Molecules 17, 3989-4006, https://doi.org/10.3390/molecules17043989

Berney M., Hammes F., Bosshard F., Weilenmann H.-U., Egli T., 2007. Assessment and interpretation of bacterial viability by using the LIVE/DEAD BacLight kit in combination with flow cytometry. Appl. Environ. Microbiol. 73, 3283-3290, https:// doi.org/10.1128/AEM.02750-06

Bouhdid S., Abrini J., Zhiri A., Espuny M.J., Manresa A., 2009. Investigation of functional and morphological changes in Pseudomonas aeruginosa and Staphylococcus aureus cells induced by Origanum compactum essential oil. J. Appl. Microbiol. 106, 1558-1568, https://doi.org/10.1111/j.13652672.2008.04124.x

Burt S., 2004. Essential oils: their antibacterial properties and potential applications in foods -a review. Int. J. Food Microbiol. 94, 223-253, https://doi.org/10.1016/j.ijfoodmicro.2004.03.022

Demir E., Sarica Ş., Özcan M.A., Suiçmez M., 2003. The use of natural feed additives as alternatives for an antibiotic growth promoter in broiler diets. Br. Poult. Sci. 44, Suppl. 2, 44-45, https://doi.org/10.1080/713655288

Deris Z.Z., Akter J.., Sivanesan S., Roberts K.D., Thompson P.E. Nation R.L., Li J., Velkov T., 2014. A secondary mode of action of polymyxins against Gram-negative bacteria involves the inhibition of NADH-quinone oxidoreductase activity. J. Antibiot. 67, 147-151, https://doi.org/10.1038/ja.2013.111

Di Pasqua R., Hoskins N., Betts G., Mauriello G., 2006. Changes in membrane fatty acids composition of microbial cells induced by addiction of thymol, carvacrol, limonene, cinnamaldehyde, and eugenol in the growing media. J. Agric. Food Chem. 54, 2745-2749, https://doi.org/10.1021/jf052722|

Fairbrother J.M., Nadeau É., Gyles C.L., 2005. Escherichia coli in postweaning diarrhea in pigs: an update on bacterial types, pathogenesis, and prevention strategies. Anim. Health Res. Rev. 6, 17-39, https://doi.org/10.1079/AHR2005105

Gill A.O., Holley R.A., 2004. Mechanisms of bactericidal action of cinnamaldehyde against Listeria monocytogenes and of eugenol against $L$. monocytogenes and Lactobacillus sakei. Appl. Environ. Microbiol. 70, 5750-5755, https://doi.org/10.1128/ AEM.70.10.5750-5755.2004

Grela E.R., Krusiński R., Matras J., 1998. Efficacy of diets with antibiotic and herb mixture additives in feeding of growingfinishing pigs. J. Anim. Feed Sci. 7, Suppl. 1, 171-175, https://doi.org/10.22358/jafs/69965/1998

Hashemi S.R., Davoodi H., 2010. Phytogenics as new class of feed additive in poultry industry. J. Anim. Vet. Adv. 9, 2295-2304, https://doi.org/10.3923/javaa.2010.2295.2304

Hayouni E.A., Bouix M., Abedrabba M., Leveau J.-Y., Hamdi M., 2008. Mechanism of action of Melaleuca armillaris (Sol. Ex Gaertu) Sm. essential oil on six LAB strains as assessed by multiparametric flow cytometry and automated microtiterbased assay. Food Chem. 111, 707-718, https://doi. org/10.1016/j.foodchem.2008.04.044
Helander I.M., Alakomi H.-L., Latva-Kala K., Mattila-Sandholm T., Pol I., Smid E.J., Gorris L.G.M., von Wright A., 1998. Characterization of the action of selected essential oil components on Gram-negative bacteria. J. Agric. Food Chem. 46, 3590-3595, https://doi.org/10.1021/jf980154m

Kantas D., Papatsiros V.G., Tassis P.D., Athanasiou L.V., Tzika E.D., 2015. The effect of a natural feed additive (Macleaya cordata), containing sanguinarine, on the performance and health status of weaning pigs. Anim. Sci. J. 86, 92-98, https:// doi.org/10.1111/asj.12240

Khattak F., Ronchi A., Castelli P., Sparks N., 2014. Effects of natural blend of essential oil on growth performance, blood biochemistry, cecal morphology, and carcass quality of broiler chickens. Poult. Sci. 93, 132-137, https://doi.org/10.3382/ps.2013-03387

Ku Y.-H., Lee M.-F., Chuang Y.-C., Chen C.-C., Yu W.-L., 2015. In vitro activity of colistin sulfate against Enterobacteriaceae producing extended-spectrum $\beta$-lactamases. J. Microbiol. Immunol. Infect. 48, 699-702, https://doi.org/10.1016/j.jmii.2013.11.005

Leclerc S., Boerlin P., Gyles C., Dubreuil J.D., Mourez M., Fairbrother J.M., Harel J., 2007. paa, originally identified in attaching and effacing Escherichia coli, is also associated with enterotoxigenic E. coli. Res. Microbiol. 158, 97-104, https://doi. org/10.1016/j.resmic.2006.09.004

Linder K., Oliver J.D., 1989. Membrane fatty acid and virulence changes in the viable but nonculturable state of Vibrio vulnificus. Appl. Environ. Microbiol. 55, 2837-2842

Manini E., Danovaro R., 2006. Synoptic determination of living/dead and active/dormant bacterial fractions in marine sediments. FEMS Microbiol. Ecol. 55, 416-423, https://doi.org/10.1111/j.15746941.2005.00042.x

Mikulášová M., Chovanová R., Vaverková Š., 2016. Synergism between antibiotics and plant extracts or essential oils with efflux pump inhibitory activity in coping with multidrug-resistant staphylococci. Phytochem. Rev. 15, 651-662, https://doi. org/10.1007/s11101-016-9458-0

Nazzaro F., Fratianni F., De Martino L., Coppola R., De Feo V., 2013. Effect of essential oils on pathogenic bacteria. Pharmaceuticals 6, 1451-1474, https://doi.org/10.3390/ph6121451

Novo D., Perlmutter N.G., Hunt R.H., Shapiro H.M., 1999. Accurate flow cytometric membrane potential measurement in bacteria using diethyloxacarbocyanine and a ratiometric technique. Cytometry 35, 55-63, https://doi.org/10.1002/(SICl)10970320(19990101)35:1<55::AID-CYTO8>3.0.CO;2-2

Oliver J.D., 2010. Recent findings on the viable but nonculturable state in pathogenic bacteria. FEMS Microbiol. Rev. 34, 415-425, https://doi.org/10.1111/j.1574-6976.2009.00200.x

Paparella A., Taccogna L., Aguzzi I., Chaves-López C., Serio A. Marsilio F., Suzzi G., 2008. Flow cytometric assessment of the antimicrobial activity of essential oils against Listeria monocytogenes. Food Control 19, 1174-1182, https://doi. org/10.1016/j.foodcont.2008.01.002

Regulation (EC) No 1831/2003 of the European Parliament and of the Council of 22 September 2003 on additives for use in animal nutrition. O. J. L268, 18.10.2003, pp. 29-43

Shen S., Zhang T., Yuan Y., Lin S., Xu J., Ye H., 2015. Effects of cinnamaldehyde on Escherichia coli and Staphylococcus aureus membrane. Food Control 47, 196-202, https://doi. org/10.1016/j.foodcont.2014.07.003

Somolinos M., García D., Condón S., Mackey B., Pagán R., 2010. Inactivation of Escherichia coli by citral. J. Appl. Microbiol. 108, 1928-1939, https://doi.org/10.1111/j.1365-2672.2009.04597.x

Stiefel P., Schmidt-Emrich S., Maniura-Weber K., Ren Q., 2015. Critical aspects of using bacterial cell viability assays with the fluorophores SYTO9 and propidium iodide. BMC Microbiol. 15, 36, https://doi.org/10.1186/s12866-015-0376-x 
Stocks S.M., 2004. Mechanism and use of the commercially available viability stain, BacLight. Cytometry 61A, 189-195, https://doi. org/10.1002/cyto.a.20069

Tiihonen K., Kettunen H., Bento M.H.L., Saarinen M., Lahtinen S., Ouwehand A.C., Schulze H., Rautonen N., 2010. The effect of feeding essential oils on broiler performance and gut microbiota. Br. Poult. Sci. 51, 381-392, https://doi.org/10.108 0/00071668.2010.496446

Velkov T., Thompson P.E., Nation R.L., Li J., 2010. Structure-activity relationships of polymyxin antibiotics. J. Med. Chem. 53 , 1898-1916, https://doi.org/10.1021/jm900999h

Velkov T., Roberts K.D., Nation R.L., Thompson P.E., Li J., 2013. Pharmacology of polymyxins: new insights into an 'old' class of antibiotics. Future Microbiol. 8, 711-724, https://doi. org/10.2217/fmb.13.39
Xu J., Zhou F., Ji B.-P., Pei R.-S., Xu N., 2008. The antibacterial mechanism of carvacrol and thymol against Escherichia coli. Lett. Appl. Microbiol. 47, 174-179, https://doi.org/10.1111/ j.1472-765X.2008.02407.x

Yahav D., Farbman L., Leibovici L., Paul M., 2012. Colistin: new lessons on an old antibiotic. Clin. Microbiol. Infect. 18, 18-29, https://doi.org/10.1111/j.1469-0691.2011.03734.x

Yang C., Chowdhury M.A., Huo Y., Gong J., 2015. Phytogenic compounds as alternatives to in-feed antibiotics: potentials and challenges in application. Pathogens 4, 137-156, https:// doi.org/10.3390/pathogens4010137 